EESTI NSV TEADUSTE AKADEEMIA TOIMETISED. IX KOIDE FOOSIKALIS-MATEMAATILISTE JA TEHNILISTE TEADUSTE SEERIA. 1960, NR. 3

ИЗВЕСТИЯ АКАДЕМИИ НАУК ЭСТОНСКОЙ ССР. ТОМ IX СЕРИЯ ФИЗИКО-МАТЕМАТИЧЕСКИХ И ТЕХНИЧЕСКИХ НАУК. 1960, № 3

\title{
ИССЛЕДОВАНИЕ ИЗМЕНЕНИЙ СОСТАВА ЖИДКОЙ ФАЗЫ ВО ВРЕМЯ СХВАТЫВАНИЯ И ПЕРВОНАЧАЛЬНОГО ОТВЕРДЕВАНИЯ СЛАНЦЕЗОЛЬНОГО КАМНЯ
}

\author{
Е. А. ГАЛИБИНА, \\ кандидат технических наук \\ Н. Л. ДИЛАКТОРСКИИ, \\ доктор геолого-минералогических наук
}

Процессы, происходящие в начальной стадии отвердевания, определяют большинство строительных свойств изделий: плотность, деформативность, долговечность, механическую прочность, морозостойкость и т. д.

В связи с тем, что воздействие на свойства различного вида бетонов с целью получения наилучших строительных свойств наиболее эффективно в момент формирования структуры вяжущего, исследования химического состава растворов, образующихся в момент схватывания и первоначального отвердевания сланцезольного камня, представляют не только теоретический, но и практический интерес.

Цель описываемой работы заключалась в том, чтобы показать изменения химического состава, происходящие в жидкой фазе сланцезольного камня во время его схватывания и первоначального отвердевания.

В качестве исходного материала была использована зола факельного сжигания сланца (кукерсита) из ТЭЦ № 2 в Кохтла-Ярве, предварительно размолотая в шаровой мельнице до удельной поверхности $2800 \mathrm{~cm}^{2} /$ г (по Товарову). Характеристика ее приведена в табл. 1.

Химический состав исходного материала

Таблища 1

Содержание окислов, \% на сухое вещество

\begin{tabular}{|c|c|c|c|c|c|c|c|c|c|c|c|}
\hline $\mathrm{SiO}_{2}$ & $\mathrm{Al}_{2} \mathrm{O}_{3}$ & $\mathrm{Fe}_{2} \mathrm{O}_{3}$ & $\mathrm{CaO}$ & $\mathrm{MgO}$ & $\begin{array}{l}\mathrm{K}_{2} \mathrm{O}+ \\
\mathrm{Na}_{2} \mathrm{O}\end{array}$ & $\mathrm{CO}_{2}$ & $\mathrm{SO}_{3}$ & $\begin{array}{c}\text { Химически } \\
\text { связанная } \\
\text { вода }\end{array}$ & Йтого & $\begin{array}{c}\mathrm{SiO}_{2} \\
\text { раств. }\end{array}$ & $\begin{array}{l}\mathrm{CaO} \\
\text { своб. }\end{array}$ \\
\hline 31,37 & 8,60 & 5,65 & 41,44 & 3,47 & 2,54 & 1,98 & 4,84 & 0,88 & 100,77 & 17,16 & 19,35 \\
\hline
\end{tabular}

Для изучения истинных растворов, возникающих во время схватывания и отвердевания, применялся метод пресс-фильтрации. Состоял он в 1ом, что сланцезольное тесто нормальной консистенции тщательно перемешивалось в течение 5 минут и во избежание высыхания и карбонизации помещалось в воздушно-влажное пространство (эксикатор с водой).

При изучении растворов, возникающих в сланцезольном тесте при повышенной температуре $\left(80^{\circ}\right)$, тесто нормальной консистенции после 5-минутного перемешивания помещалось в паровую камеру. Через определенные сроки, соответствующие при нормальном затвердевании 
5 -30 минутам, $2,4,6,8$ и 24 часам, а при пропарке - 30 минутам, 2 и 4 часам, часть теста отделялась от общего замеса и переносилась в стальной цилиндр, после чего из него при помощи поршня под давлением $2000 \mathrm{kr} / \mathrm{cm}^{2}$ выдавливалась жидкая фаза, отделявшаяся от мути фильтрованием под разрежением.

$\mathrm{B}$ составе жидкой фазы определялись: $\mathrm{SiO}_{2}$ и $\mathrm{Al}_{2} \mathrm{O}_{3}$ - фотоколориметрически, $\mathrm{CaO}$ - объемным методом с помощью трилона, $\mathrm{K}_{2} \mathrm{O}+\mathrm{Na}_{2} \mathrm{O}$ - в виде сернокислых солей после выделения из водного раствора всех других катионов, $\mathrm{SO}_{3}$ - осаждением в виде $\mathrm{BaSO}_{4}, \mathrm{Cl}^{\prime}-$ осаждением в виде хлористого серебра, которое взвешивалось после сушки при $130^{\circ}$. $\mathrm{OH}^{\prime}$-ионы определялись титрованием жидкой фазы $0,1 n$ раствором $\mathrm{HCl}$. Величина водородного показателя определялась потенциометрически с помощью стеклянного электрода.

Исследованию подвергались растворы, выдавленные из сланцезольного теста нормальной консистенции, из теста, затворенного на воде комнатной температуры, на горячей воде $\left(65^{\circ}\right)$ и на $0,5 \%$-ном растворе глюкозы.

Содержание отдельных ионов в выдавленных растворах в зависимости от времени, условий твердения и вида введенных в золу добавок показано в табл. 2.

Фиг. 1. Изменение концентрации извести в растворе в зависимости от времени и условий твердения. Пылевидная сланцевая зола, затворенная на: $a$ - воде комнатной температуры, $6-0,5 \%$-ном растворе глюкозы, в - горячей $\left(65^{\circ}\right)$ воде (во всех трех случаях твердение происходит в нормальных условиях); 2 - пылевидная сланцевая зола $+\mathrm{H}_{2} \mathrm{O}$ (пропарка при $80^{\circ}$ ).

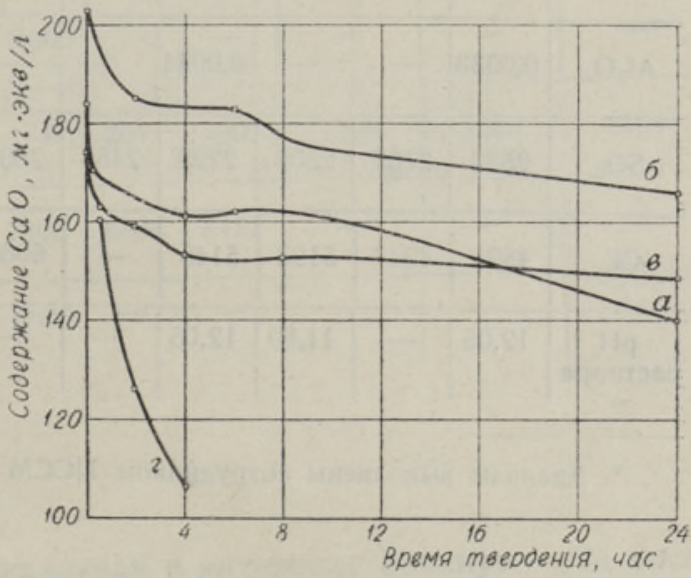

Анализ изменений концентрации извести в выдавленных растворах, представленных на фиг. 1, указывает на зависимость этой величины не только от времени твердения, но и от вида введенных в золу добавок, а также от условий твердения сланцезольного теста.

Сразу после затворения сланцевой золы водою образуются пересыщенные окисью кальция растворы, степень пересыщения которых зависит от условий твердения сланцезольного теста. После 5-минутного твердения последнего концентрация извести в растворе при $\mathrm{pH}=12$ составляет 184,57 мг · экв/литр. Добавка поверхностно-активных веществ, в частности затворение сланцевой золы $0,5 \%$-ным раствором глюкозы, повышает, а горячей водою $\left(65^{\circ}\right)$ понижает концентрацию извести в растворе. После пяти минут твердения она составляет соответственно 204,28 и 174,85 мг -экв/литр. Независимо от вида введенных в золу добавок, концентрация извести в интервале 5 минут - 24 часа твердения падает. Однако к 24 часам твердения ее величина во всех случаях превышает концентрацию чистой извести в насыщенном водном растворе и достигает 140,71 мг·экв/литр. 
Состав жидкой фазы сланцезольного камня на разных стадиях его отвер

\begin{tabular}{|c|c|c|c|c|c|c|c|c|c|c|c|c|}
\hline & & & & & & & & & $\mathrm{H}$ & O p M & $a \pi b$ & $\mathrm{HOC}$ \\
\hline & & & & & & & & 4 & e p e & 3 & & \\
\hline & & 5 мину & & & 30 мин & & & 2 часе & & & 4 час & \\
\hline & & Затвор & ено на & & Затво & ено на & & Затвор & ено на & & Затвор & ено на \\
\hline 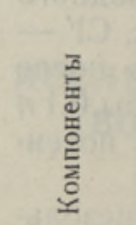 & 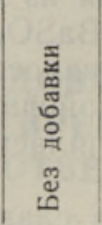 & 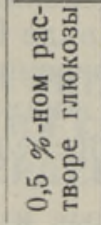 & 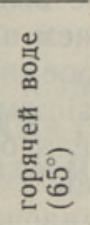 & 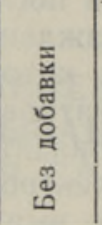 & 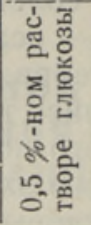 & 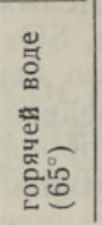 & 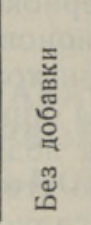 & 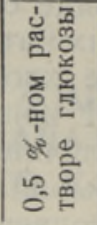 & 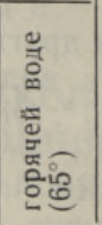 & 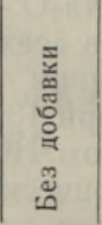 & 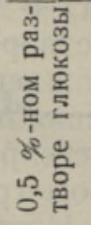 & 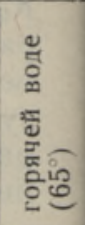 \\
\hline $\mathrm{CaO}$ & 5168 & 5720 & 4896 & 4650 & 5520 & 4569 & 4460 & 5190 & 4474 & 4527 & 5248 & 4297 \\
\hline $\begin{array}{l}\mathrm{K}_{2} \mathrm{O}+ \\
+\mathrm{Na}_{2} \mathrm{O}\end{array}$ & 3110 & 3826 & 4215 & 3280 & 3740 & 4259 & 4320 & 3820 & 4907 & 3830 & 3840 & 4548 \\
\hline $\mathrm{SiO}_{2}$ & 0,004 & 0,004 & - & - & 0,004 & - & - & 0,004 & - & 0,0032 & 0,004 & - \\
\hline $\mathrm{Al}_{2} \mathrm{O}_{3}$ & 0,0033 & - & - & 0,0044 & -- & - & - & - & - & - & - & - \\
\hline $\mathrm{SO}_{3}$ & 2524 & 2757 & 2304 & 2222 & 2455 & 2030 & 1885 & 2287 & 2030 & 1783 & 2340 & 1893 \\
\hline $\mathrm{Cl}^{\prime}$ & 4830 & 4247 & 5193 & 5145 & - & 6060 & 5406 & 4741 & 6480 & 6523 & 4733 & 6576 \\
\hline$\underset{\text { раствора }}{\mathrm{pH}}$ & 12,05 & - & 11,80 & 12,05 & - & - & - & - & - & 11,70 & - & -- \\
\hline
\end{tabular}

* Анализы выполнены сотрудником ИССМ АН ЭССР Л. Тамм.

Обраб́отка сланцезольного теста при повышенной температуре $\left(80^{\circ}\right)$ способствовала сильному понижению концентрации извести в растворах. В этом случае после 30 минут твердения величина концентрации ионов Са ${ }^{\prime}$ составляла 160,00 против 166,07 мг · экв/л, а после двух часов твердения - 126,07 против 159,28 мг-экв/л при нормальном твердении (фиг. 1, кривая 2). В растворах, выдавленных в интервале 5 минут 24 часа твердения, с течением времени наблюдалось понижение концентрации не только ионов $\mathrm{Ca}{ }{ }$, но и $\mathrm{OH}^{\prime}$.

Концентрация ионов $\mathrm{OH}^{\prime}$ в жидкой фазе сланцезольного теста зависела не только от времени твердения, но и от вида добавок, введенных в сланцевую золу, и соответственно уменьшалась при твердении систем: сланцевая зола, затворенная на $0,5 \%$-ном растворе глюкозы, зола, затворенная на воде комнатной температуры, и зола, затворенная на горячей воде $\left(65^{\circ}\right)$ (фиг. $\left.2 A\right)$.

Измерение величины $\mathrm{pH}$ растворов указало, во-первых, на меньшее значение этой величины для растворов, затворенных на комнатной и горячей воде, по сравнению с растворами, выдавленными из сланцезольного теста, затворенного на 0,5\%-ном растворе глюкозы, и, во-вторых, 
Таблица 2

девания в зависимости от вида добавок и условий твердения (мг/литр)*

\begin{tabular}{|c|c|c|c|c|c|c|c|c|c|c|c|}
\hline \multicolumn{9}{|c|}{ твердение } & \multicolumn{3}{|c|}{$\begin{array}{c}\text { Пропаривание при } 80^{\circ} \\
\text { (зола без добавок) }\end{array}$} \\
\hline \multicolumn{3}{|c|}{6 часов } & \multicolumn{3}{|c|}{8 часов } & \multicolumn{3}{|c|}{24 часа } & \multicolumn{3}{|c|}{ Через } \\
\hline \multirow[b]{2}{*}{ 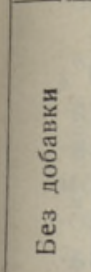 } & \multicolumn{2}{|c|}{ Затворено на } & \multirow[b]{2}{*}{ 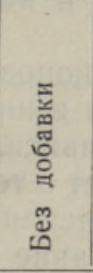 } & \multicolumn{2}{|c|}{ Затворено на } & \multirow[b]{2}{*}{ 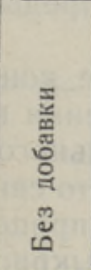 } & \multicolumn{2}{|c|}{ Затворено на } & \multirow[b]{2}{*}{30 минут } & \multirow[b]{2}{*}{2 часа } & \multirow[b]{2}{*}{4 часа } \\
\hline & 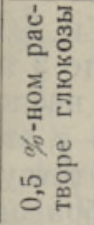 & 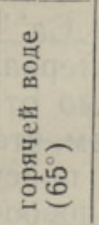 & & 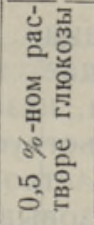 & 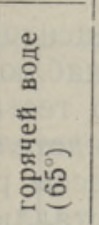 & & 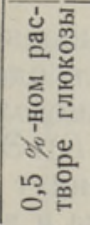 & 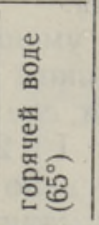 & & & \\
\hline 4554 & 5140 & 4270 & 一 & 4950 & 4297 & 3940 & 4810 & 4170 & 4480 & 3530 & 2990 \\
\hline 5670 & 4020 & 5440 & - & - & 6050 & 6053 & 4730 & 8460 & 4117 & 7637 & 10370 \\
\hline 0,0048 & 0,005 & - & - & 0,005 & - & - & 0,004 & - & 0,0037 & 0,005 & 0,002 \\
\hline 0,004 & - & - & 0,005 & - & - & 0,005 & - & - & - & - & - \\
\hline 1842 & 2740 & 1900 & - & 2250 & 1838 & 1749 & 2017 & 1800 & 2160 & 2538 & 4184 \\
\hline 6927 & 5384 & - & - & 5500 & 7059 & 7306 & 6308 & 8461 & - & - & - \\
\hline - & - & - & - & 11,62 & - & 11,55 & - & - & - & - & - \\
\hline
\end{tabular}

на уменьшение водородного показателя в интервале 5 минут -24 часа твердения с 12 до 11,5 для вяжущего, затворенного на комнатной и горячей воде.

Известно, что концентрация ионов $\mathrm{SO}_{4}{ }_{4}$ в растворе и поведение их при твердении сланцезольного камня, ввиду возможности образования гидросульфоалюмината кальция, может играть огромную роль в момент образования скелетного сростка. Изучение скорости растворения присутствующего в сланцевой золе ангидрита в зависимости от условий твердения и вида действующих на раствор добавок показало, что с течением времени в образующихся в период твердения растворах происходит понижение концентрации ионов $\mathrm{SO}^{\prime \prime}{ }_{4}$. Следует отметить, что к 24 часам твердения концентрация ионов $\mathrm{SO}_{4}{ }_{4}$ в растворе, независимо от первоначальной, была практически равной во всех исследованных нами растворах (фиг. 25$)$. Совершенно иная картина наблюдалась в растворах, выдавленных из сланцезольного теста, подвергнутого пропариванию при $80^{\circ}$. В этих условиях увеличение времени твердения способствовало неуклонному повышению содержания ионов $\mathrm{SO}_{4}^{\prime \prime}$ при постоянном и довольно большом понижении концентрации ионов $\mathrm{Ca}^{*}$ (фиг. 25 , кривая г). 
Понижение концентрации ионов $\mathrm{Ca}{ }^{*}$ и $\mathrm{SO}_{4}{ }_{4}$ в растворах (в случае твердения сланцезольного теста в нормальных условиях) можно объяснить, с одной стороны, перекристаллизацией новообразований гидроокиси кальция и двуводного гипса, а с другой стороны - образованием менее растворимых, чем $\mathrm{Ca}(\mathrm{OH})_{2}$ и $\mathrm{CaSO}_{4} \cdot 2 \mathrm{H}_{2} \mathrm{O}$, соединений, содержащих ионы $\mathrm{Ca}$ “ и $\mathrm{SO}_{4}{ }_{4}$. Таким соединением в твердеющем сланцезольном камне, как показали работы предыдущих лет [1], является гидросульфоалюминат кальция.

Весьма интенсивное уменьшение концентрации ионов $\mathrm{Ca}{ }{ }_{\text {и }} \mathrm{SO}_{4}$ в растворах при нормальном твердении наблюдается в интервале 5 минут - 4 часа твердения сланцезольного теста, независимо от введенных в золу добавок (фиг. 1 и 2 Б). Это свидетельствует о том, что в этом интервале весьма интенсивно идут процессы растворения присутствующих в золе извести и ангидрита и выкристаллизовывание новообразований. Вместе с тем это говорит и о том, что основная масса гидросульфоалюмината кальция, возникающего за счет взаимодействия нерастворимого алюмината кальция и растворимого сернокислого кальция, образуется именно в этом интервале твердения. Судя по величине водородного показателя ( $\mathrm{pH}=12)$, при твердении сланцезольного камня образуется трехсульфатная форма $3 \mathrm{CaO} \cdot \mathrm{A}_{2} \mathrm{O}_{3} \cdot 3 \mathrm{CaSO}_{4} \cdot 31 \mathrm{H}_{2} \mathrm{O}\left[{ }^{2}\right]$. Проведенная работа показала также, что в составе жидкой фазы сланцезольного камня, твердеющего в интервале 5 минут - 24 часа, наряду с ионами $\mathrm{Ca}^{*}$ и $\mathrm{SO}_{4}^{\prime \prime}$ присутствуют ионы $\mathrm{K}^{*}$ и $\mathrm{Cl}^{\prime}$.

Присутствие ионов $\mathrm{Cl}^{\prime}$ в растворах является, по данным Л. Ойт *, одной из причин коррозии арматуры в сланцезольном железобетоне, в связи с чем определение концентрации ионов хлора в растворах сланцезольного камня, твердеющего как с добавками, так и без них, представляет большой интерес.

Наличие ионов $\mathrm{K}^{*}$ в жидкой фазе такого рода вяжущих, какими являются сланцевые золы, содержащие в своем составе $30 \%$ шлаковых частиц, имеет важное значение для процессов, происходящих при твердении сланцезольных вяжущих, ввиду возможности активации стекловатых частиц щелочными растворами.

Данные, представленные на фиг. $2 B$ и $2 \Gamma$ и характеризующие содержание ионов $\mathrm{K}^{*}$ и $\mathrm{Cl}^{\prime}$ в твердеющем без добавок сланцезольном тесте, показывают, что концентрация этих ионов в значительной степени зависит от времени твердения сланцезольного камня. Замечено, что резкое увеличение концентрации ионов $\mathrm{K}^{*}$ и $\mathrm{Cl}^{\prime}$ в растворах сланцезольного камня происходит в интервале 5 минут - 6 часов твердения; в дальнейшем же, начиная с шести часов твердения и вплоть до 24 часов, концентрация ионов $\mathrm{K}^{*}$ и $\mathrm{Cl}^{\prime}$ изменяется весьма незначительно.

Затворение сланцевой золы на 0,5\%-ном растворе глюкозы приводит к резкому уменьшению, а затворение на горячей воде - к резкому увеличению концентрации ионов $\mathrm{K}^{*}$ и $\mathrm{Cl}^{\prime}$ в выдавленных растворах по сравнению с растворами, полученными из сланцезольного теста, затворенного на воде комнатной температуры.

Твердение сланцезольного камня в условиях повышенных температур $\left(80^{\circ}\right)$ приводит к значительному увеличению концентрации ионов $\mathrm{K}^{*}$ и $\mathrm{Cl}^{\prime}$ в растворе.

Содержание $\mathrm{SiO}_{2}$ и $\mathrm{Al}_{2} \mathrm{O}_{3}$ (табл. 2) в жидкой фазе сланцезольного теста, твердеющего в нормальных условиях, составляет 0,004 мг/литр и в течение 24 часов твердения сланцезольного камня практически не изменяется.

* Л. В. О йт, Коррозия арматуры в сланцезольном бетоне, Научный отчет. ИССМ АН ЭССР, Таллин, 1958. 

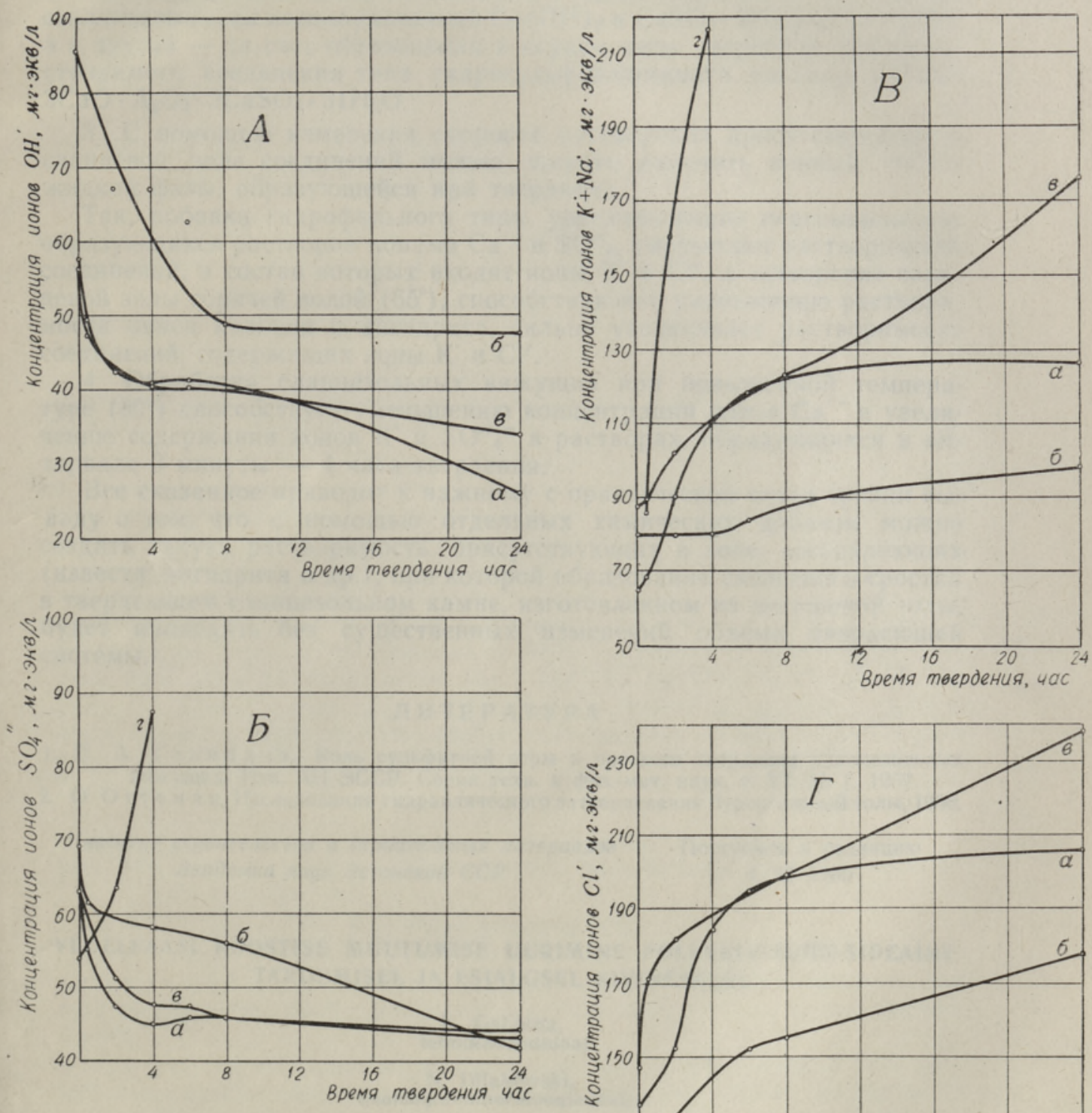

Фиг. 2. Изменение концентрации ионов $\mathrm{OH}^{\prime}(A)$, $\mathrm{SO}_{4}^{\prime \prime}(\bar{b}), \mathrm{K}^{*}+\mathrm{Na}^{*}(B)$ и $\mathrm{Cl}^{\prime}(\Gamma)$ в сланцезольном растворе твердеющей пылевидной золы в зависимости от времени твердения и вида введенных в золу добавок. (Обозначения те же, что на фиг. 1).

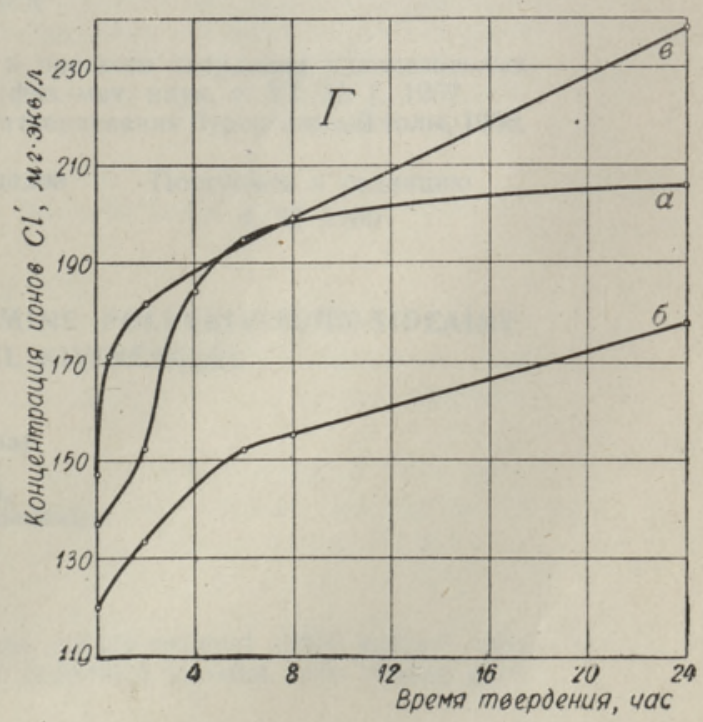




\title{
Выводы
}

1. Сразу после затворения пылевидной сланцевой золы водою образуются сильно пересыщенные окисью кальция растворы, содержащие значительное количество ионов $\mathrm{SO}_{4}{ }_{4}$.

2. Понижение с течением времени концентрации ионов $\mathrm{Ca}{ }^{*}, \mathrm{SO}_{4}{ }_{4}$ и $\mathrm{OH}^{\prime}$ в твердеющем камне происходит, с одной стороны, за счет выкристаллизовывания новообразований $\mathrm{Ca}(\mathrm{OH})_{2}$ и $\mathrm{CaSO}_{4} \cdot 2 \mathrm{H}_{2} \mathrm{O}$ из раствора, a с другой - за счет образования в первые часы твердения труднорастворимого соединения типа гидросульфоалюмината кальция состава $3 \mathrm{CaO} \cdot \mathrm{A}_{2} \mathrm{O}_{3} \cdot 3 \mathrm{CaSO}_{4} \cdot 31 \mathrm{H}_{2} \mathrm{O}$.

3. С помощью изменения скорости растворения присутствующих в сланцевой золе соединений можно широко изменять ионный состав жидкой фазы, образующейся при твердении.

Так, добавки гидрофильного типа, увеличивающие пересыщенность образующихся растворов ионами $\mathrm{Ca}{ }^{\text {и }} \mathrm{SO}^{\prime \prime}{ }_{4}$, уменьшают растворимость соединений, в состав которых входят ионы $\mathrm{K}^{*}$ и $\mathrm{Cl}^{\prime}$, а затворение сланцевой золы горячей водой $\left(65^{\circ}\right)$, способствующее уменьшению растворимости окиси кальция и ангидрита, сильно увеличивает растворимость соединений, содержащих ионы $\mathrm{K}^{*}$ и $\mathrm{Cl}^{\prime}$.

4. Обработка сланцезольных вяжущих при повышенной температуре $\left(80^{\circ}\right)$ способствует уменьшению концентрации ионов $\mathrm{Ca}^{*}$ и увеличению содержания ионов $\mathrm{K}^{*}$ и $\mathrm{SO}_{4}{ }_{4}$ * в растворах, образующихся в интервале 3 минуты - 4 часа твердения.

Все сказанное приводит к важному с практической точки зрения выводу о том, что с помощью отдельных химических добавок можно создать такую растворимость присутствующих в золе составляющих (извести, ангидрита и др.), при которой образование скелетного сростка в твердеющем сланцезольном камне, изготовленном из негашеной золы, будет проходить без существенных изменений объема твердеющей системы.

\section{ЛИТ Е Р А Т У Р А}

1. Е. А. Г али бина, Роль сульфатной серы в процессе твердения сланцезольных вяжущих, Изв. АН ЭССР. Серия техн. и физ.-мат. наук, т. VI, № 1, 1957.

2. О. О т те м а н, Исследования гидравлического затвердевания буроугольной золы, 1950.

Ннститут строительства и строительных материалов Академии наук Эстонской ССР
Поступила в редакцию

4. II 1960

\section{VEDELFAASI KOOSTISE MUUTUMISE UURIMINE POLLEVKIVITUHK-SIDEAINE TARDUMISEL JA ESIALGSEL KIVINEMISEL}

\author{
E. Galibina, \\ tehnikakandidaat \\ N. Dilaktorski, \\ geoloogia-mineraloogiadoktor \\ Resümee
}

Uuriti vedelfaasi keemilist koostist peale tema väljapressimist $\left(2000 \mathrm{~kg} / \mathrm{cm}^{2}\right.$ rōhu ail) kivinevast pōlevkivituhk-sideainest. Selgus, et vedelfaasi koostist võib laiades piirides muuta:

* Ионы $\mathrm{Cl}^{\prime}$ в растворе не определялись. 
a) hüdrofiilset liiki lisanditega, mis suurendavad moodustuvate lahuste üleküllastust $\mathrm{Ca} \cdot$ - ja $\mathrm{SO}_{4}{ }^{\prime \prime}$-iooniga ning samal ajal vähendavad kaaliumi ja kloori sisaldavate ühendite lahustuvust;

b) põlevkivituhk-sideaine segamisel kuuma veega, mis vähendab tunduvalt kaltsiuınoksüüdi ja anhüdriidi lahustuvust, tōstab aga $\mathrm{K}$ - ja $\mathrm{Cl}^{\prime}$-iooni kontsentratsiooni;

c) pōlevkivituhk-sideaine aurutamisel kõrgemal temperatuuril, mis pōhjustab Cäiooni kontsentratsiooni vähenemise ning $\mathrm{K}$ - ja $\mathrm{SO}_{4}{ }^{\prime \prime}$-iooni kontsentratsiooni suurenemise.

Olaltoodust võib teha tähtsa praktilise järelduse: põlevkivituhk-sideaine mōnedele koostisosadele (lubi, anhüdriit jt.) on vöimalik anda sellised lahustuvusomadused, millede puhul kustutamata tuha kivinemisel toimub skelett-struktuuri moodustumine ilma oluliste mahumuutusteta.

Eesti NSV Teaduste Akadeemia

Ehitlise ja Ehitusmaterjalide Instituut
Saabus toimetusse

4. II 1960

\section{BESTANDSVERÄNDERUNGN DER FLUSSIGEN PHASE BEI DER ERSTARRUNG UND ERSTER ERHARTUNG DES BRENNSCHIEFERASCHE-BINDEMITTELS}

\section{E. Galibina, N. Dilaktorski}

\section{Zusammenfassung}

Es wurde die chemische Zusammensetzung der flüssigen Phase nach deren Herauspressung (unter einem Druck von $2000 \mathrm{~kg} / \mathrm{cm}^{2}$ ) aus dem erhartenden BrennschieferascheBindemittel untersucht. Dabei zeigte es sich, dass die Zusammensetzung der flüssigen Phase in weiten Grenzen verändert werden kann, und zwar:

a) durch Beimischungen hydrophiler Art, welche die Obersättigung der entstehenden Lösungen mit $\mathrm{Ca}{ }^{\prime}$ - und $\mathrm{SO}_{4}{ }^{\prime \prime}$ - Ionen steigern, gleichzeitig aber die Löslichkeit der kaliumund chlorhaltigen Verbindungen vermindern;

b) durch Verrühren des Brennschieferasche-Bindemittels mit heissem Wasser, was die Löslichkeit von Kalziumoxyd und Anhydrit bedeutend herabsetzt, die Konzentration der

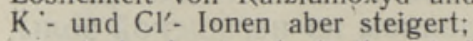

c) durch eine hydrothermische Behandlung des Brennschieferasche-Bindemittels bei höherer Temperatur, was die Konzentration der $\mathrm{Ca}$ "-Ionen vermindert und die Konzentration der $\mathrm{K}^{\prime}$ - und $\mathrm{SO}_{4}^{\prime \prime}$-Ionen vergrössert.

Obiges gestattet die wichtige praktische Folgerung zu ziehen, dass es möglich ist, einigen Bestandteilen des Brennschieferasche-Bindemittels (Kalk, Anhydrit u.a.) Lösbarkeitseigenschaften $\mathrm{zu}$ verleihen, welche die Entstehung der Skelett-Struktur bei der Erhartung ungelöschter Asche ohne wesentliche Veränderungen des Volumens vor sich gehen lassen.

Institut für Bauwesen und Baumaterialien der Akademie der Wissenschaiten der Estnischen SSR
Eingegangen am 4. Febr. 1960 